\title{
Introduction to the First Special Issue
}

The journal of "Informatics in Education" has decided to start publishing of Special Issues once a year. This is a reward to guest editors, who have extended the cooperation and relationship with authors, and this way have augmented the visibility of discussed academic topics in the academic research community.

The first special issue is devoted to Pedagogy of Computational Thinking and Programming. Computational thinking skills, forming the basis for programming and coding, is at the same time the logical base for programming concepts. On the one hand, it has become a subject of international awareness regarding preschool, primary, and secondary levels of education, on the other hand, computational thinking still remains a narrow field, which is taught at the level of higher education and computing skills development is rather limited in certain occupational groups.

Children and young adults are now growing up in a world that is markedly different from that witnessed by previous generations, where computers, mobile phones, the Internet and social media networks are predominantly intertwined with daily life activities. As a result, their approach to problem solving, learning experiences, and thinking skills have significantly changed.

However, the knowledge of how to use technologies is forming an important part of our life today, and the actual understanding of the rationale, which is behind these technologies, are two the very different propositions.

Learning the basic concepts, related to computer science and programming, learners can better understand the digital world, in which they live, and at the same time they can improve the quality of their connections to the world. Learning of programming, as well as their understanding of the logic of science, that controls these new technologies, lie behind the entertainment, which technologies have brought about. This has become a much larger discovery, both for young children and for young adults. As a result, it contributes to their digital transformations. In this context, programming becomes one of the basic digital literacy skills important for the contemporary digital age.

The general-purpose programming languages, commonly used today for adults, are text-based, but the use of graphic-based tools for children and young adults are increasing. The tools and methods used in teaching of programming are being enriched with different hardware-based tools: starting from programming of toys at the introductory level, moving to unplugged activity-based computer science applications, adopting game and creative drama approaches, and finally, the advanced physical and robotic programming. 
In this context, looking from a pedagogical perspective, this special issue aims at bringing together different applications and approaches to the educational process of programming at different ages and levels, within the triangle of software, hardware and method. In addition to analyses of literature reviews and unplugged activities, there are block-based programmes, mobile-based approaches and computing behaviours discussed in this issue. Although a limited number of articles can be published within this special issue, the articles chosen to be published have the potential for future studies, will hopefully be of interest to many researchers and encourage them to find the effective ways of teaching programming across all education levels.

I would like to thank all the authors, who have contributed to this special issue and shared their pedagogical experiences of teaching computational thinking and programming.

Guest Editor

Prof. Dr. Yasemin GÜLBAHAR

Ankara University

Turkey 